\title{
Ceramic Proton and Mixed Proton-Electron Conductors in Membranes for Energy Conversion Applications
}

\author{
Truls NORBY \\ Department of Chemistry, University of Oslo, FERMIO, \\ Gaustadalleen 21, NO-0349 Oslo, Norway
}

Keywords: Fuel Cells, Hydrogen Separation Membranes, Proton Conductors

Ceramic high temperature proton conductors offer in principle great advantages over oxide ion conductors and "proton conducting" polymers as electrolytes in fuel cells. This is related to the absence of product water on the anode, and simplified overall water management. The state-of-the-art proton conducting perovskite oxide materials are too basic to be stable in operation with reformed fossil fuels, and new classes of more stable proton conducting oxides have been discovered-so far with more moderate proton conductivities, though. Also new mixed proton-electron conducting oxides are being uncovered, and it is shown how they can be utilized as membranes in fossil fuelled power plants with $\mathrm{CO}_{2}$ sequestration.

\section{Introduction}

Oxide ion conducting oxides have been in use since Nernst (1897) developed his lamp based on yttriastabilised zirconia (YSZ) more than a century ago. Later it came into focus for use in solid oxide fuel cells (SOFCs) along with other oxide ion conductors that have been discovered since. The alternative polymer electrolyte membrane (PEM) fuel cells have been advancing the last decade, and is currently the leading fuel cell technology. The PEMs swell by hydration and contain hydrophilic channels with water in which protons are mobile. The operation temperature is normally below $100^{\circ} \mathrm{C}$, while some new high temperature PEMs go somewhat higher. While SOFCs transport $\mathrm{O}^{2-}$ ions, the PEMs transport hydrated $\mathrm{H}_{3} \mathrm{O}^{+}$ions. Water molecules accompanying the proton in the latter require water management. True proton, $\mathrm{H}^{+}$, conductors are oxidic (oxides, phosphates, sulphates, etc.), with protons jumping between host oxide ions. They comprise solid acids such as $\mathrm{CsHSO}_{4}$ and $\mathrm{CsH}_{2} \mathrm{PO}_{4}$ and analogues, which are excellent proton conductors, but melt typically at $200-300^{\circ} \mathrm{C}$ and are water-soluble. Finally, true proton conductors comprise nominally proton- and water-free compounds; oxides and oxysalts such as phosphates. They combine pure proton transport with high temperature stability, but suffer from a compromise (Norby, 1999): They have considerable activation energies for proton jumps that require high tem-

Received on September 5, 2007; accepted on September 26, 2007. Correspondence concerning this article should be addressed to T. Norby (E-mail address: truls.norby@kjemi.uio.no). Presented at International Symposium on Innovative Materials for Processes in Energy Systems, IMPRES, Kyoto, October, 2007. peratures, where reversible dehydration sets in. This limits the proton conductivity to typically $10^{-2} \mathrm{~S} / \mathrm{cm}$, achievable at $600-800^{\circ} \mathrm{C}$. Moreover, this is the bulk value for $\mathrm{Sr}$ - or $\mathrm{Ba}$-based perovskites, which are sensitive to $\mathrm{CO}_{2}$ and $\mathrm{H}_{2} \mathrm{O}$ at intermediate temperatures. The challenge is to develop new Sr- and Ba-free oxides with low activation energy for proton transport and favourable hydration (protonation) thermodynamics. This review describes progress in this respect and potential advantages of the fuel cells obtained. Phosphates are more stable with respect to, e.g., $\mathrm{CO}_{2}$, but evaporation of phosphorous under reducing conditions reduces their potential uses to moderate temperatures.

Mixed (ambipolar) proton electron conduction gives rise to hydrogen permeability and can be utilized in hydrogen separation membranes for, e.g., fossil-fired power plants with $\mathrm{CO}_{2}$ sequestration; We will discuss materials requirements and progress.

\section{Proton Conducting Oxides and Phosphates}

\subsection{General principles}

Protons dissolve in oxidic ceramics in equilibrium with water vapour at high temperatures, often to a sufficient degree that the material becomes proton conducting or mixed proton-electron conducting. A common approach is to acceptor-dope the material, creating positively charged compensating defects, notably oxygen vacancies, then hydrate these;

$$
\mathrm{H}_{2} \mathrm{O}(\mathrm{g})+\mathrm{v}_{\mathrm{O}}^{\bullet \bullet}+\mathrm{O}_{\mathrm{O}}^{\mathrm{x}}=2 \mathrm{OH}_{\mathrm{O}}^{\bullet}
$$

For some oxides this reaction is largely exothermic and driven to the right, while for others it is driven left 
even at moderate temperatures. Favourable hydration thermodynamics and high mobility of the protons are found in Ba- and Sr-based II-IV perovskites (Norby et al., 2004). Proton conductivity exceeding $0.01 \mathrm{~S} / \mathrm{cm}$ is thus found in, e.g., acceptor-doped $\mathrm{BaCeO}_{3}$ and $\mathrm{BaZrO}_{3}$. Other classes such as rare earth oxides $\mathrm{Ln}_{2} \mathrm{O}_{3}$ and phosphates $\mathrm{LnPO}_{4}$ are more easily hydrated as the rare earth gets smaller, but then lose proton mobility, so that the conductivity ends up lower than for the perovskites.

An alternative to acceptor doping is to use compounds with inherent (structural) deficiency of oxygen. If we consider these oxygen "vacancies" as ordered (interstitial sites) and that protons dissolve randomly on regular oxygen sites, we get

$$
\mathrm{H}_{2} \mathrm{O}(\mathrm{g})+\mathrm{v}_{\mathrm{i}}^{\mathrm{x}}+2 \mathrm{O}_{\mathrm{O}}^{\mathrm{x}}=\mathrm{O}_{\mathrm{i}}^{\prime \prime}+2 \mathrm{OH}_{\mathrm{O}}^{\bullet}
$$

(An alternative is that one proton associates with the interstitial oxide ion so that the two charge compensating defects are $\mathrm{OH}_{\mathrm{i}}^{\prime}$ and $\mathrm{OH}_{\mathrm{O}}^{\bullet}$.) During such hydration, the remaining oxygen "vacancies" may disorder and the protons (hydroxide ions) may eventually order. These processes have been observed in, e.g., $\mathrm{Sr}_{4}\left(\mathrm{Sr}_{2} \mathrm{Ta}_{2}\right) \mathrm{O}_{11}$ hydrating to $\mathrm{Sr}_{4}\left(\mathrm{Sr}_{2} \mathrm{Ta}_{2}\right) \mathrm{O}_{10}(\mathrm{OH})_{2}$ (Schober, 2006) and $\mathrm{Ba}_{2} \mathrm{In}_{2} \mathrm{O}_{5}$ hydrating to $\mathrm{Ba}_{2} \mathrm{In}_{2} \mathrm{O}_{4}(\mathrm{OH})_{2}$ (Fischer et al., 1999). However, the proton conductivity has remained moderate as it has not been possible so far to fully hydrate these phases without ordering the protons. In a broader sense, no hydroxide or oxyhydroxide has been shown to disorder or in other ways (doping, nonstoichiometry) exhibit high defect concentrations and thus high proton conductivity in the solid state.

As a parallel to hydration of ordered structural oxygen vacancies, we may also foresee hydration of disordered, yet structural vacancies (in the sense that they are part of the stoichiometric composition and structure). This appears to be the case in mayenite, $\mathrm{Ca}_{12} \mathrm{Al}_{14} \mathrm{O}_{33}-\mathrm{a}$ compound with a charged framework and one oxide ion compensating this, residing randomly in one of six structural cages. Hydration replaces the oxide ion and one empty cage with two hydroxide ions in cages (Hayashi et al., 2005).

For hydrogen separation membranes it is also of interest to identify oxides in which protons according to the abovementioned defect models are accompanied by minor concentrations of mobile electrons-so as to give rise to mixed conduction. This is what appears to be the situation in acceptor-doped $\mathrm{SrCeO}_{3}$. Alternatively, one may skip the acceptor doping and inherent oxygen deficiency, and instead dissolve hydrogen as protons and electrons:

$$
\mathrm{H}_{2}(\mathrm{~g})+2 \mathrm{O}_{\mathrm{O}}^{\mathrm{x}}=2 \mathrm{OH}_{\mathrm{O}}^{\bullet}+2 \mathrm{e}^{\prime}
$$

This dominates the defect structure of $\mathrm{ZnO}$ under reducing conditions (Thomas and Lander, 1956).

Regardless of route to high concentrations of mobile protons, the protons in all the systems we have considered migrate by jumping from one oxide ion host to another. The activation energy for these jumps mostly lies in the dynamics of the oxide ion host lattice, since the two oxide ions must "collide" in order to be close enough for the proton to make the transfer. Thus, large soft lattices with space for vibrant oxide ions typically provide the highest proton mobilityhence the good proton conduction in many Ba-containing perovskites and in acid oxysalts of heavy and large, soft, alkali cations.

\subsection{Recent developments; proton conductors}

Oxides that are chemically more stable than the typical perovskite proton conductors are in great demand. An interesting candidate is acceptor-doped $\mathrm{LaScO}_{3}$ - a perovskite-related material but without the alkaline earth component. The hydration is favourable, and it attains proton conductivities of around $10^{-3} \mathrm{~S} / \mathrm{cm}$ (Nomura et al., 2004). However, Sc is prohibitively expensive.

Recently, new classes of oxides with oxide ion tetrahedra rather than the perovskites' octahedra have gained attention. Acceptor-doped rare earth niobates and tantalates have been shown to be fairly pure proton conductors (Haugsrud and Norby, 2006). The solubility of dopants is only of the order of $1 \mathrm{~mol} \%$, probably because of the high energy cost of the accompanying defect in tetrahedra-based structures. Ca-doped $\mathrm{LaNbO}_{4}$ has shown the highest proton conductivity, around $10^{-3} \mathrm{~S} / \mathrm{cm}$ in humid atmospheres at around $700^{\circ} \mathrm{C}$. They exhibit a monoclinic to tetragonal phase transformation at a temperature that increases with decreasing rare earth radius and increases on going from $\mathrm{Nb}$ to Ta. The lowest transformation temperature is thus found for $\mathrm{LaNbO}_{4}$, around $500^{\circ} \mathrm{C}$. The high temperature tetragonal phase exhibits higher proton conductivity than the monoclinic. The monoclinic phase is ferroelastic, and forms twins upon stresses from thermal expansion, etc. Thus, the material is mechanically robust and survives the phase transformation well in our experience. Other materials with oxygen tetrahedra have also emerged as proton conductors, e.g., acceptor-substituted $\mathrm{La}_{3} \mathrm{NbO}_{7}$ (Shimura et al., 2002) and $\mathrm{LaBaGaO}_{4}$ (Schönberger et al., 2005) both with proton conduction in the $10^{-4} \mathrm{~S} / \mathrm{cm}$ range.

The new, stable non-perovskite proton conductors generally have resistive grain boundaries, but the problem seems to be less severe than for the best perovskite proton conductors such as $\mathrm{BaZrO}_{3}$.

Proton conduction in acceptor-doped rare earth orthophosphates $\mathrm{LnPO}_{4}$ is well known since Norby and Christiansen (1995). A number of rare earth meta- and oxy-phosphates, borates and silicates are also proton conductors (see for instance Amezawa et al., 2006) with 
similarly modest proton conductivity. Eulytite-structured $\mathrm{Bi}_{4}\left(\mathrm{SiO}_{4}\right)_{3}$ (Kitamura et al., 2007) and $\mathrm{Ba}_{3} \mathrm{La}\left(\mathrm{PO}_{4}\right)_{3}$ are also recently identified as proton conductors, but with grain boundary resistance and functionality of dopants still under investigation (Sharova et al., 2007).

Pyrophosphates of tetravalent cations have recently come in focus because of reports of very high proton conductivity in $\mathrm{SnP}_{2} \mathrm{O}_{7}$ and $\mathrm{TiP}_{2} \mathrm{O}_{7}$, pure or with In substitution (Nagao et al., 2006). The proton conductivity peaks at $200-250^{\circ} \mathrm{C}$, for In-substituted $\mathrm{SnP}_{2} \mathrm{O}_{7}$ at conductivities as high as $0.1 \mathrm{~S} / \mathrm{cm}$. It is unclear, however, what causes this; acceptor-doping and hydration of $\mathrm{P}_{2} \mathrm{O}_{7}{ }^{4-}$ are possible, but influence of a liquid phase resulting from hydration of excess $\mathrm{P}_{2} \mathrm{O}_{5}$ seems more likely. Others have investigated $\mathrm{TiP}_{2} \mathrm{O}_{7}$ at high temperatures $\left(400-1200^{\circ} \mathrm{C}\right)$ and found the material to be a modest proton conductor (Norby et al., 2006).

Hydration of pyrophosphate groups exemplifies hydration of inherent structural oxygen deficiency, analogous to Eq. (2). Another example is lanthanum oxoborate $\mathrm{La}_{26} \mathrm{O}_{27}\left(\mathrm{BO}_{3}\right)_{8}$ in which a 28 th oxo-site is vacant and can be hydrated, to obtain lanthanum oxyhydroxy-borate $\mathrm{La}_{26} \mathrm{O}_{26}(\mathrm{OH})_{2}\left(\mathrm{BO}_{3}\right)_{8}$. The latter has stable proton conductivity of the order of $10^{-3} \mathrm{~S} / \mathrm{cm}$ in wet atmospheres at $700^{\circ} \mathrm{C}$ (Noirault et al., 2007).

\subsection{Recent developments; mixed conductors}

Historically, acceptor-doped $\mathrm{SrCeO}_{3}$ (and to some extent $\mathrm{BaCeO}_{3}$ ) has been the state-of-the-art mixed proton-electron conductor for hydrogen permeable membranes. $\mathrm{SrCeO}_{3}$-based materials exhibit protonic and electronic n-type conductivities, both around $10^{-2}$ $\mathrm{S} / \mathrm{cm}$ in wet hydrogen at $1000^{\circ} \mathrm{C}$. This gives an acceptable ambipolar conductivity if the membrane is present as a thin film. Surface kinetics limitations have so far not been found to affect hydrogen permeation in such membranes. But they cannot be foreseen to survive for long in $\mathrm{CO}_{2}$-containing feed gases from reforming stages.

Among the new classes of oxidic proton conductors more stable towards $\mathrm{CO}_{2}$ mentioned above, none have much electronic conduction under the mildly reducing conditions required, and the phosphates are in addition susceptible of hazardious evaporation as $\mathrm{PH}_{3}(\mathrm{~g})$.

Following an early indication (Shimura et al., 2001), rare earth tungstates $\mathrm{Ln}_{6} \mathrm{WO}_{12}$ have been investigated systematically, undoped and nominally acceptor doped (Haugsrud, 2007). $\mathrm{La}_{6} \mathrm{WO}_{12}$ exhibits proton conduction as an electrolyte at intermediate temperature, and at higher temperatures the mixed, ambipolar conductivity exceeds that of acceptor-doped $\mathrm{SrCeO}_{3}$. A superior hydrogen permeability has been demonstrated (Larring et al., 2006), but the material's mechanical and chemical stability remains to be tested. Cation diffusion and $\mathrm{W}$ evaporation are two potential obstacles that need to be evaluated.

\section{Proton Conducting Fuel Cells (PCFCs)}

We now discuss proton conducting fuel cells (PCFCs) that utilise true proton conductors, as opposed to polymer or hydrous electrolytes which transport $\mathrm{H}_{3} \mathrm{O}^{+}$ions or even more hydrated species. True proton conductors need no hydration of the fuel to provide a water vehicle. Unlike oxide ion conductors, which form water on the anode (fuel) side, proton conductors form water on the cathode side. The cathode can normally be fed with an excess of air to flush water out, and sometimes this over-stoichiometry of air is already needed for cooling. In this situation, the true proton conductors offer the following advantages when hydrogen is the fuel:

i) Operating voltage remains higher during load,

ii) Fuel utilization and thus overall electrical efficiency is higher since fuel is not diluted with water and needs no recirculation,

iii) System is simplified because recirculation and water handling can be reduced or eliminated,

iv) Anode microstructure becomes less critical as there is no product gas (water) counterflow,

v) The danger that the metal anode is oxidized during too hard load is eliminated; the oxygen potential on the anode remains more constant since no water is formed there.

There is presently intensive research towards commercializing so-called solid acid fuel cells (SAFC) based on, e.g., $\mathrm{CsHSO}_{4}$ or $\mathrm{CsH}_{2} \mathrm{PO}_{4}$ (Boysen et al., 2004). Operation temperatures of $150-300^{\circ} \mathrm{C}$ and high proton conductivity are favourable, while mechanical and chemical stability are concerns.

Laboratory fuel cells based on state-of-the-art high temperature ceramic proton conductors have been demonstrated by many groups (e.g., Ito et al., 2005). However, being based on the Ba-containing perovskites such as $\mathrm{BaCeO}_{3}$, they are mechanically and chemically vulnerable. Efforts are thus at present being made to employ the more robust proton conductors like $\mathrm{LaNbO}_{4}$, but at the cost of having to make a thinner electrolyte, certainly below $10 \mu \mathrm{m}$.

Figure 1 shows a schematical fuel cell based on Ca-doped $\mathrm{LaNbO}_{4}$. In comparison with "traditional" polymer electrolyte fuel cells-where water is a vehicle for proton transport- the ceramic ones also need no water circulation.

The electrodes for PCFCs need to be developed from scratch. Since Ni possesses H solubility and diffusivity, it is reasonable to believe that Ni-electrolyte cermets can be utilized like for SOFCs. However, the new electrolytes may require entirely new microstructure and sintering strategies. It would be welcome to have good mixed proton-electron conductors as the ceramic phase, but as known from membrane 


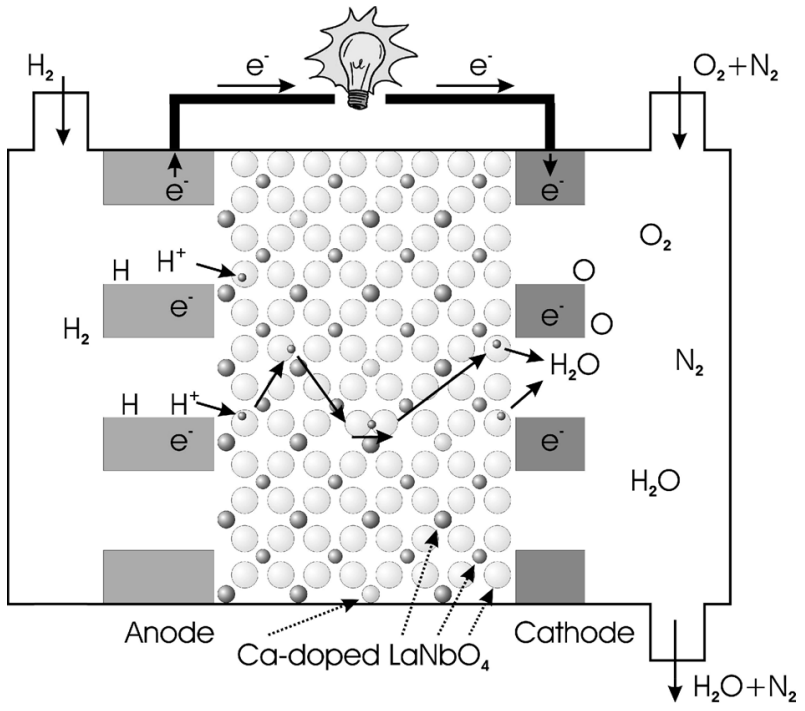

Fig. 1 Schematic $\mathrm{H}_{2}$ /air fuel cell with a true proton conducting electrolyte (Ca-doped $\mathrm{LaNbO}_{4}$ as example). Note that the fuel needs no recycling and in principle can be utilised $100 \%$. From Norby et al., 2006)

development there are no good candidates at present. This may change, but in the meantime, the metallic phase has to transport both electrons and chemical species (in this case hydrogen).

For cathodes, many perovskites are known from SOFC work that are good p-type electronic conductors, with more or less minor mixed oxide ion contribution, but proton conduction is expectedly low and they have not been systematically tested on PCFCs. It is interesting to note that most new proton conductors have $\mathrm{La}^{3+}$ as a main component, and that the same compound with full or partial replacement of $\mathrm{La}^{3+}$ by $\mathrm{Ce}^{3+}$ will cause increased tendency of oxidation (to $\mathrm{Ce}^{4+}$ ) resulting in enhanced p-type conduction. The Ce-containing compound could thus be used as interfacial layer towards the cathode or component in a ceramicceramic (cer-cer) cathode.

For the potential of the increased efficiency of the PCFC to be utilized, the cost of production must be addressed. Many new materials are based on $\mathrm{La}$, and while the electrolyte does not make up a big amount of material (as a thin film) the ceramic part of electrodes can become a major cost factor. For this it is of interest to investigate "mischmetal" strategies, i.e. investigating whether the main properties (e.g., proton conduction) are maintained if the La component is not purified with respect to other rare earths. A similar approach can be taken regarding the purity of $\mathrm{Nb}$ with respect to its sister element Ta.

As said above, proton conducting fuel cells (PCFCs) have their main advantage with $\mathrm{H}_{2}$ as fuel as in a future hydrogen society. However, also fossil fuels highly reformed and shifted to $\mathrm{H}_{2}$ and $\mathrm{CO}_{2}$ may benefit from the PCFC efficiency. They have the further potential of moderate operating temperatures, but need for thin electrolytes, plus electrode development, remain as challenges.

\section{Hydrogen Separation Membranes}

Mixed proton electron conducting oxidic materials may be used as hydrogen selective permeable membranes for sweeping hydrogen out of shifted syngas or coal gas (Norby and Haugsrud, 2006). In this case the membrane operates under altogether reducing conditions. The membrane would have to tolerate this and the presence of $\mathrm{CO}_{2}$. The membrane can be combined with an oxygen permeable membrane for partial oxidation of natural gas and creating the sweep gas, as shown in Figure 2.

Another potential use of a hydrogen permeable membrane is in creating the sweep gas in the first step by letting air draw hydrogen through a membrane to react its oxygen to steam, see Figure 3.

This membrane will see a larger span in oxygen potential and larger driving force. Also this needs to tolerate $\mathrm{CO}_{2}$. The remaining $\mathrm{N}_{2}+$ steam serves as sweep gas for the subsequent hydrogen extraction, while the depletion of $\mathrm{H}_{2}$ from the reformate drives the shift reaction forwards, and prepares the reformate for the final extraction of its remaining hydrogen. A gas-fired power plant that in this way utilises two ceramic mixed conducting membranes to produce $\mathrm{H}_{2}+\mathrm{N}_{2}+\mathrm{H}_{2} \mathrm{O}$ for a gas turbine and $\mathrm{CO}_{2}$ for deposition has been modeled to give almost the same economy as a conventional plant without $\mathrm{CO}_{2}$ sequestration. Nevertheless, technical (materials) challenges remain, related to the thin membranes required, and the characterisation of, e.g., cation diffusion and surface kinetics.

\section{Conclusions}

Proton conducting ceramics offer unique advantages in terms of efficiency, and operational flexibility and design simplicity. Mixed proton electron conducting ceramics similarly offer unique processes for $\mathrm{CO}_{2}$ sequestration in fossil-fired power plants. However, compared to the oxide ion conducting counterparts the conductivities are smaller when one excludes candidate materials that are not stable in $\mathrm{CO}_{2}$. This makes thinner membranes necessary. Furthermore, developments of complete systems may still meet obstacles. On the materials side, focus is currently on identifying materials with high chemical stability and proton conductivity higher than $10^{-3} \mathrm{~S} / \mathrm{cm}$, following approaches of hydration of oxygen vacancies from acceptor doping or inherent (structural) deficiency. 


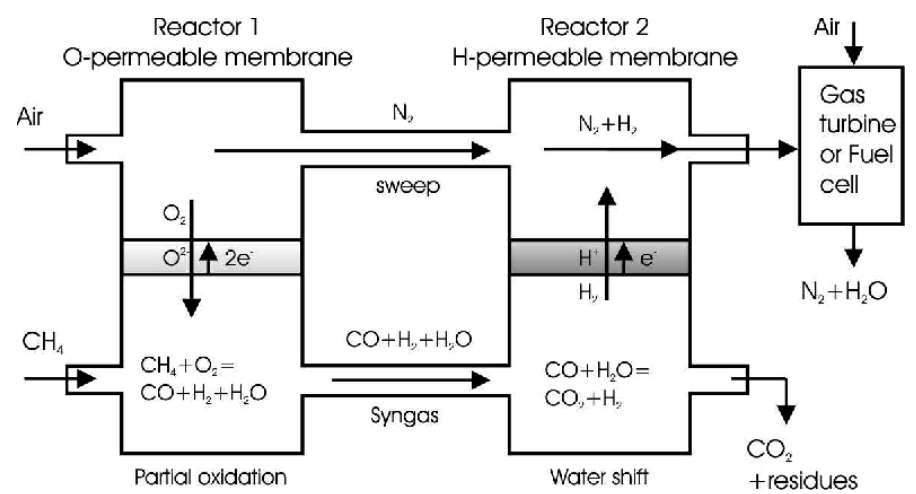

Fig. 2 Schematic simplified use of oxygen and hydrogen permeable membranes for natural gas fired power plant with $\mathrm{CO}_{2}$ sequestration

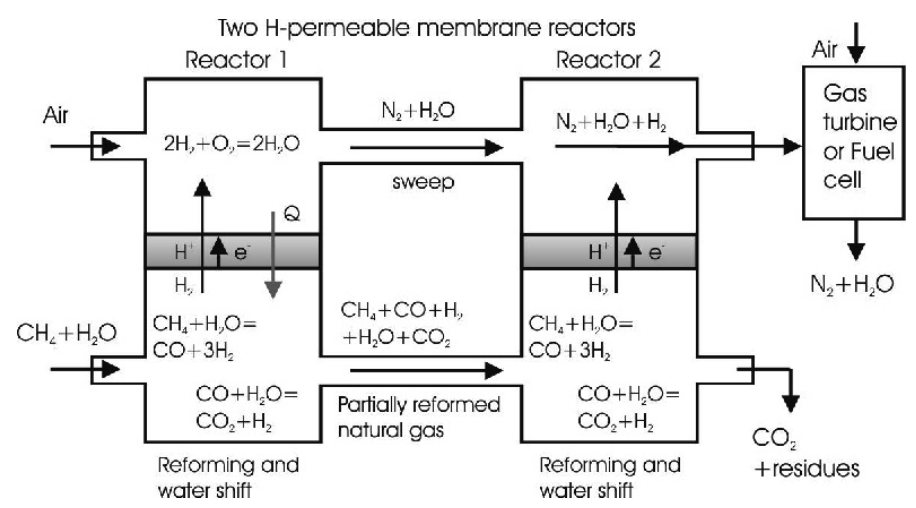

Fig. 3 Schematic simplified use of two hydrogen permeable membranes for natural gas fired power plant with $\mathrm{CO}_{2}$ sequestration. Note the heat exchange $(Q)$ that is essential in Reactor 1

\section{Acknowledgements}

The research council of Norway (RCN) (projects "Hydrogen in oxides,"FOET/Nanomat) and FUNMAT@UiO are acknowledged for support towards the subject area of this article.

\begin{tabular}{|c|c|c|}
\hline \multicolumn{2}{|c|}{ Nomenclature } & \\
\hline $\mathrm{v}_{\mathrm{o}}$ & $=$ & oxide ion vacancy, double positive charge \\
\hline $\mathrm{O}_{0}^{\mathrm{x}}$ & $=$ & normal oxide ion \\
\hline $\mathrm{OH}_{\mathrm{o}}^{*}$ & $=$ & hydroxide ion on oxide ion site; one charge \\
\hline $\mathrm{v}_{\mathrm{i}}^{\mathrm{x}}$ & $=$ & structural vacancy (empty interstitial site) \\
\hline $\mathrm{O}_{\mathrm{i}}^{\prime \prime}$ & $=$ & interstitial oxide ion; double negative char \\
\hline 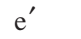 & $=$ & defect (conduction band) electron \\
\hline
\end{tabular}

\section{Literature Cited}

Amezawa, K., Y. Uchimoto and Y. Tomii; "High Temperature Protonic Conduction in Sr-Doped $\mathrm{LaP}_{3} \mathrm{O}_{9}$," Solid State Ionics, 177, 2407-2411 (2006)

Boysen, D. A., T. Uda, C. R. I. Chisholm and S. Haile; "HighPerformance Solid Acid Fuel Cells through Humidity Stabilization," Science, 303, 68-70 (2004)

Fischer, W., G. Reck and T. Schober; "Structural Transformation of the Oxygen and Proton Conductor $\mathrm{Ba}_{2} \mathrm{In}_{2} \mathrm{O}_{5}$ in Humid Air; an in-situ Powder Diffraction Study," Solid State Ionics, 116, 211215 (1999)

Haugsrud, R.; "Defects and Transport Properties in $\mathrm{Ln}_{6} \mathrm{WO}_{12}(\mathrm{Ln}=$ La, Nd, Gd, Er)," Solid State Ionics, 178, 555-560 (2007)

Haugsrud, R. and T. Norby; "Proton Conduction in Rare Earth Ortho-Niobates and Ortho-Tantalates," Nat. Mater., 5, 193-196 (2006)
Hayashi, K., M. Hirano and H. Hosono; "Thermodynamics and Kinetics of Hydroxide Ion Formation in $12 \mathrm{CaO} \cdot 7 \mathrm{Al}_{2} \mathrm{O}_{3}$, , J. Phys. Chem. B, 109, 11900-11906 (2005)

Ito, N., M. Iijima, K. Kimura and S. Iguchi; "New Intermediate Temperature Fuel Cell with Ultra-Thin Proton Conductor Electrolyte," J. Power Sources, 152, 200-203 (2005)

Kitamura, N., K. Amezawa, Y. Uchimoto, Y. Tomii and T. Hanada; "Electrical Conduction Properties of Sr-Doped $\mathrm{Bi}_{4}\left(\mathrm{SiO}_{4}\right)_{3}$ with the Eulytite-Type Structure," J. Mater. Sci., 42, 6566-6571 (2007)

Larring, L., R. Haugsrud, J. B. Smith, T. Norby and R. Bredesen; "Hydrogen Flux through Mixed Ionic-Electronic Membranes," Proc. 9th Int. Conf. Inorg. Membranes, pp. 492-495, R. Bredesen and H. Raeder eds., Lillehammer, Norway (2006)

Nagao, M., T. Kamiya, P. Heo, A. Tomita, T. Hibino and M. Sano; "Proton Conduction in $\mathrm{In}^{3+}$-Doped $\mathrm{SnP}_{2} \mathrm{O}_{7}$ at Intermediate Temperatures," J. Electrochem. Soc., 153, A1604-A1609 (2006)

Nernst, W.; "Verfahren zur Erzeugung von Elektrischem Glühlicht," German Patent 104872 (1897)

Noirault, S., S. Célérier, O. Joubert, M. T. Caldes and Y. Piffard; "Incorporation of Water and Fast Proton Conduction in the Inherently Oxygen-Deficient Compound $\mathrm{La}_{26} \mathrm{O}_{27} \cdot\left(\mathrm{BO}_{3}\right)_{8}$," $A d v$. Mater., 19, 867-870 (2007)

Nomura, K., T. Takeuchi, S. Kamo, H. Kageyama and Y. Miyazaki; "Proton Conduction in Doped $\mathrm{LaScO}_{3}$ Perovskites," Solid State Ionics, 175, 553-555 (2004)

Norby, T.; "Solid State Protonic Conductors-Principles, Properties, Progress, and Prospects," Solid State Ionics, 125, 1-11 (1999) 
Norby, T. and N. Christiansen; "Proton Conduction in Ca- and SrSubstituted $\mathrm{LaPO}_{4}$," Solid State Ionics, 77, 240-243 (1995)

Norby, T. and R. Haugsrud; "Dense Ceramic Membranes for Hydrogen Separation," Nonporous Inorganic Membranes, pp. 148, A. F. Sammells and M. V. Mundschau eds., Wiley-VCH, Weinheim, Germany (2006)

Norby, T., M. Widerøe, R. Gløckner and Y Larring; "Hydrogen in Oxides," Dalton Trans., 19, 3012-3018 (2004)

Norby, T., R. Haugsrud and Nalini Vajeeston; "New Proton Conducting Materials for Fuel Cells and Hydrogen Separation Membranes," Proc. 9th Int. Conf. Inorg. Membranes, pp. 260-267, R. Bredesen and H. Raeder eds., Lillehammer, Norway (2006)

Schober, T.; "Phase Diagrams in the Proton Conductor Systems $\mathrm{Sr}_{6} \mathrm{Ta}_{2} \mathrm{O}_{11} \cdot n \mathrm{H}_{2} \mathrm{O}$ and $\mathrm{Sr}_{5.92} \mathrm{Ta}_{2.08} \mathrm{O}_{11.12} \cdot n \mathrm{H}_{2} \mathrm{O}$," Solid State Ionics, 177, 471-474 (2006)
Schönberger, F., E. Kendrick, M. S. Islam and P. Slater; "Investigation of Proton Conduction in $\mathrm{La}_{1-x} \mathrm{Ba}_{1+x} \mathrm{GaO}_{4-x / 2}$ and $\mathrm{La}_{1-x}$ $\mathrm{Sr}_{2+x} \mathrm{GaO}_{5-x / 2}$," Solid State Ionics, 176, 2951-2953 (2005)

Sharova, N., H. Fjellvåg and T. Norby; "Proton Conductivity in $\mathrm{Sr}$ Doped $\mathrm{Ba}_{3} \mathrm{La}\left(\mathrm{PO}_{4}\right)_{3}$," Ext. Abst. and Poster, p. 595, Solid State Ionics XVI, Shanghai, China (2007)

Shimura, T., S. Fujimoto and H. Iwahara; "Proton Conduction in Non-Perovskite-Type Oxides at Elevated Temperatures," Solid State Ionics, 143, 117-123 (2001)

Shimura, T., Y. Tokiwa and H. Iwahara; "Protonic Conduction in Lanthanum Strontium Aluminate and Lanthanum Niobate-Based Oxides at Elevated Temperatures," Solid State Ionics, 154/155, 653-658 (2002)

Thomas, D. G. and J. J. Lander; "Hydrogen as a Donor in Zinc Oxide," J. Chem. Phys., 25, 1136-1142 (1956) 